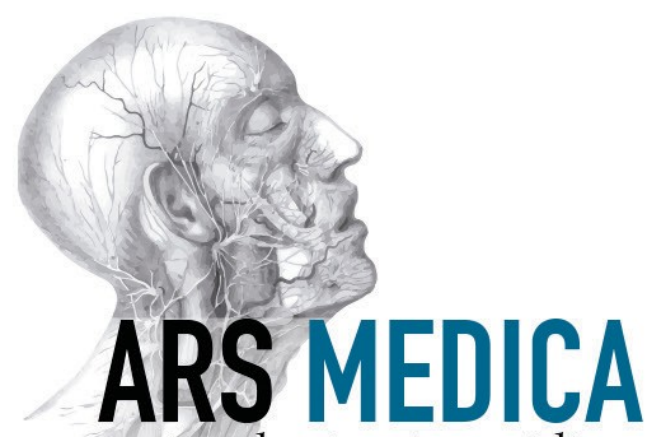

El presente artículo corresponde a un archivo originalmente publicado en Ars Medica, revista de estudios médicos humanísticos, actualmente incluido en el historial de Ars Medica Revista de ciencias médicas. El contenido del presente artículo, no necesariamente representa la actual línea editorial. Para mayor información visitar el siguiente vínculo: http://www.arsmedica.cl/index.php/MED/about/submissions\#authorGuidelines 


\title{
Aborto inducido, séptico y shock séptico
}

\author{
Dr. Omar Sandoval Muñoz \\ Instructor Asociado \\ Hospital Dr. Sótero del Río \\ Departamento de Obstetricia y Ginecología \\ Pontificia Universidad Católica de Chile
}

\section{Resumen}

El aborto provocado séptico en Chile estuvo por varias décadas dentro de las primeras causasde mortalidad materna, y en 1960 la tasa de mortalidad materna por aborto era de 107/100.000 NV. El desarrollo y progreso en diversas áreas de nuestro país, sumado a las políticas sanitarias implementadas gubernamentalmente, han logrado disminuir la mortalidad materna por aborto de manera muy significativa, siendo ésta de 0.8/100.000 NV en 2005 y manteniéndose estable y por debajo de 1.5/100.000 NV desde el 2001 en adelante. En el presente artículo se revisa y compara el perfil epidemiológico de la mujer que actualmente se realiza un aborto y además se aborda el diagnóstico y tratamiento médico desde la perspectiva gineco-obstétrica.

palabras clave: aborto; aborto séptico; mortalidad; sepsis.

\section{INDUCED ABORTION, SEPTIC ABORTION AND SEPTIC SHOCK}

In Chile induced septic abortion was one of main causes of maternal death for several decades. In 1960 maternal mortality ratio (MMR) associated to abortion was 107 per 100.000live births. Development an progress in a wide range of areas in addition to government's family planning policies in our country have reduced the MMR associated to abortion significatively to 0.8 /100.000 live births in 2005 and have kept it under 1.5/100.000 live births since 2001. In this article we review and compare the epidemiologic profile of women who undergo an induced abortion and we approach to diagnosis and medical treatment from de gyneco-obstetric perspective.

Key words: abortion; septic abortion; mortality; sepsis.

\section{Introducción}

El aborto es la interrupción del embarazo antes de que el feto alcance suviabilidad. Formalmente este límite ha sido definido antes de las 22 semanas o antes de que el feto alcance los 500 gramos de peso. Desde el punto de vista morfológico y funcional, sin embargo, la viabilidad se lograría al momento en que se une el bronquiolo terminal con el alvéolo pulmonar, 
evento que ocurre alrededor de las 25 semanas de gestación. No obstante, se debe considerar todo el avance tecnológico y recursos humanos disponibles en el lugar geográfico donde ocurra la interrupción del embarazo.

En el aborto inducido o provocado existe la voluntad materna y de la persona que realiza la interrupción. De este modo pueden definirse tres situaciones diferentes, dependiendo de la legislación vigente en cada país o lugar en que se analiza el problema:

-Aborto provocado, ilegal o criminal cuando no existe ley que lo autoricey habitualmente es por motivaciones maternas.

-Aborto inducido legal, en el cual existen las mismas motivaciones maternas pero está permitido por la legislación.

-Aborto terapéutico, con el fin de salvaguardar la integridad física o lavida materna y también debe estar regido legalmente. Se debe considerarque con los avances tecnológicos actuales prácticamente no existe una condición médica que amerite interrumpir un embarazo para salvar la vidamaterna, debido a que el desarrollo de la neonatología y la perinatología permiten rescatar niños desde las 24 semanas de gestación.

En 1960 la mortalidad por aborto en nuestro país era de 107/100.000 Nacidos Vivos (NV), constituyendo una de las principales causas de mortalidad materna, y en 2005 descendió a $0.8 / 100.000$ NV y se ha mantenido estable y bajo 1.5/100.000 NV desde el $2001(1,2)^{1}$.

Este logro es muy significativo y nos diferencia notablemente del resto de los países de Latinoamérica en los últimos años. Gran parte de este cambio fue determinada por la introducción de los métodos anticonceptivos en la década de los años 1960 y el progresivo desarrollo social y económico de los últimos 40 años en nuestro país $(1,2,3,6)^{2}$.

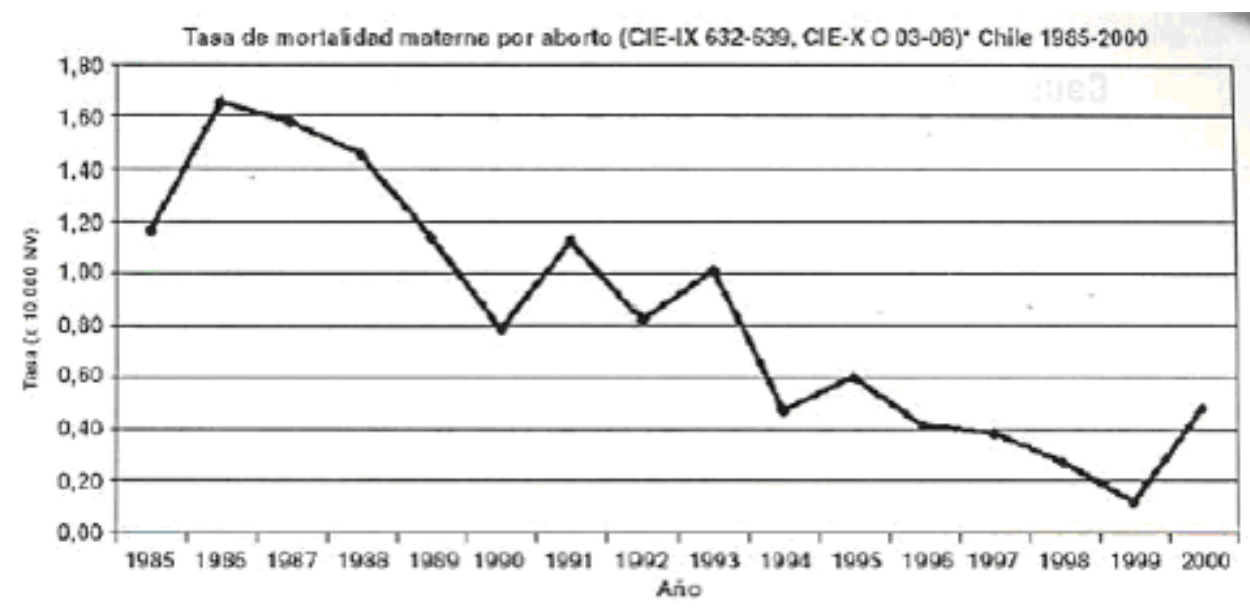


Copiado de: Szot J., Moreno C. Mortalidad por aborto en Chile. Análisis epidemiológico 1985-2000. Rev Chil Obstet Ginecol 2003; 68(4): 309-314.

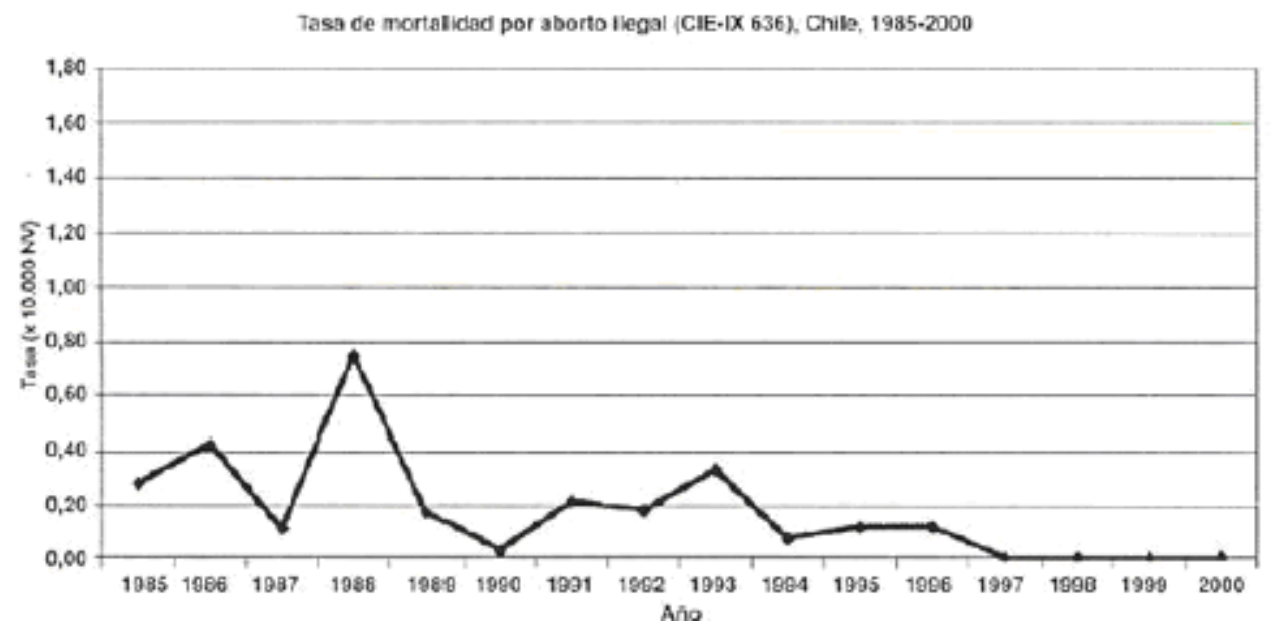

Copiado de: Szot J., Moreno C. Mortalidad por aborto en Chile. Análisis epidemiológico 1985-2000. Rev Chil Obstet Ginecol 2003; 68(4): 309-314.

El aborto séptico corresponde a la interrupción espontánea o inducida de la gestación, en la cual el mecanismo de producción del aborto, o sus consecuencias, son la infección del producto de la concepción o los anexos ovulares.

\section{Caracterización epidemiológica de las mujeres que se practican aborto y etiología}

La gran mayoría de los estudios sobre el aborto en nuestro país corresponde a las décadas de 1950 a 1980. Esto se explica por su incidencia en la tasa de mortalidad materna ubicándose dentro de las primeras causas de mortalidad. Diversas acciones implementadas por el Ministerio de Salud han conseguido una progresiva y marcada disminución en la mortalidad materna y en especial en la mortalidad poraborto. No se puede descartar tampoco el uso de fármacos como el misoprostol, que puede ser adquirido incluso a través de internet.

No existen estadísticas confiables respecto de la incidencia y prevalencia del aborto provocado por el hecho de ser ilegal y punible, y por la censura del entorno social. Se estima que el $40 \%$ de los abortos corresponde a abortos sépticos, y alrededor del 60-68\% de las pacientes reconocía maniobras abortivas, constituyendo así su etiología más frecuente $(10)^{3}$.

El perfil de la mujer que se realiza un aborto ha cambiado en los últimos años. 
Clásicamente se describía la edad de mayor incidencia entre los 21 a 25 años seguida por el rango de 26-30 años. Habitualmente eran multíparas de 1 o 2 hijos. No se observaba gran diferencia en estado civil. Alrededor del $45 \%$ repetía el abortoy hasta un $49 \%$ lo hacía por tercera vez. Casi todos eran realizados en el primer trimestre y antes de las 10 semanas de gestación. Las motivaciones fundamentales eran económicas e hijos no deseados $\mathrm{y}$, en menor proporción, problemas conyugales.Otro factor era la falla del método anticonceptivo $(7,8,10)$.

En una revisión no publicada del Hospital Dr. Sótero del Río en los años 1999 y 2000 en 34 pacientes que reconocieron maniobras abortivas y que correspondían al $12 \%$ de los abortos sépticos, cerca del $50 \%$ eran menores de 20 años y el 58,8\% eran nuligestas $(12)^{4}$.

\begin{tabular}{|l|c|c|}
\hline \multicolumn{2}{|c|}{ Abortos 1999-2000 Hospital Dr. Sótero del Río } \\
\hline Año & 1999 & 2000 \\
\hline Egresos por aborto & 970 & 831 \\
\hline $\begin{array}{l}\text { Abortos sépticos } \\
\text { c/maniobras }\end{array}$ & 22 & 16 \\
\hline $\begin{array}{l}\text { Abortos sépticos } \\
\text { s/maniobras }\end{array}$ & 150 & 118 \\
\hline
\end{tabular}

$\operatorname{Edad}(\mathrm{N}=34)$

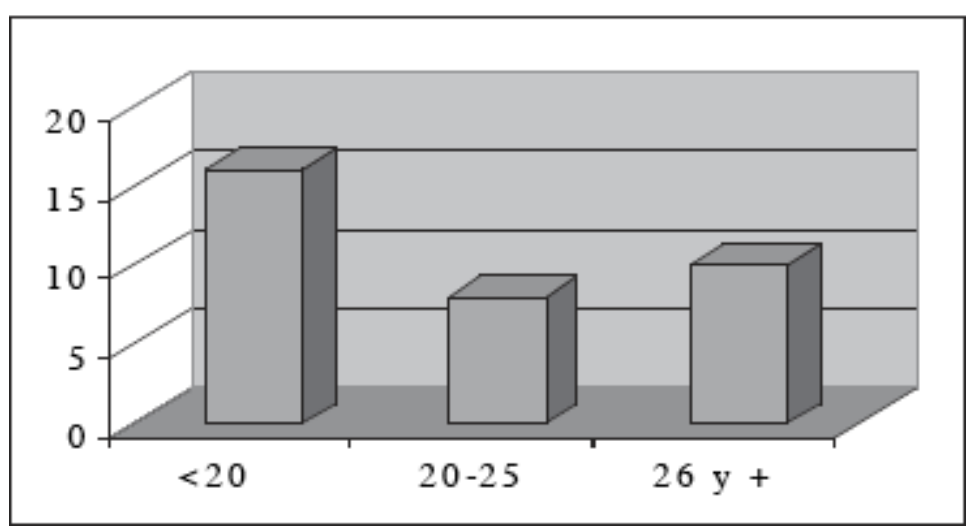




\section{Paridad ( $\mathbf{N}=\mathbf{3 4})$}

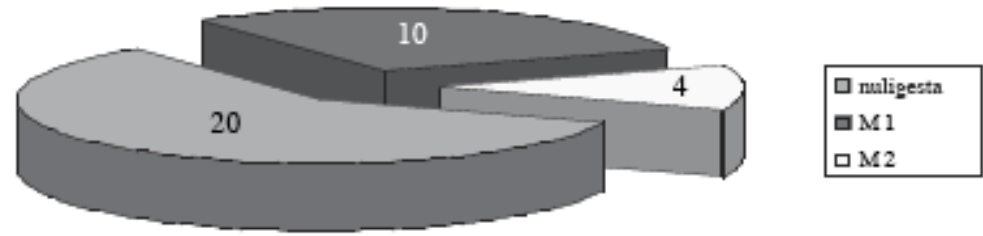

Pérez A., Donoso E. $3^{\circ}$ Ed. Publicaciones Técnicas Mediterráneo Ltda. Santiago Chile 1999. Cáp. 29, pág. 431-450. Espinoza L., et al. Estudio clínico epidemiológico del aborto en mujeres chilenas. Rev Chil Obstet Ginecol 1985; 50: 278-285. Sandoval O. Datos no publicados. Abortos19992000 Hospital Dr. Sótero del Río.

\section{Uso de método anticonceptivo $(\mathrm{N}=34)$}

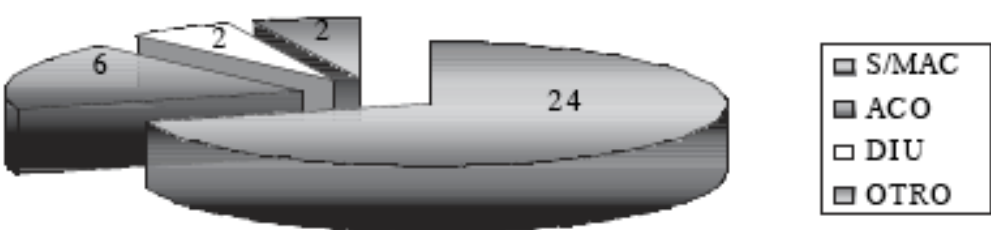

El 70,5\% no usaba métodos anticonceptivos, el $88 \%$ no se controlaba el embarazo, y sólo el 26,5\% tenía pareja estable (12)

Control de embarazo y pareja estable $(\mathrm{N}=34)$

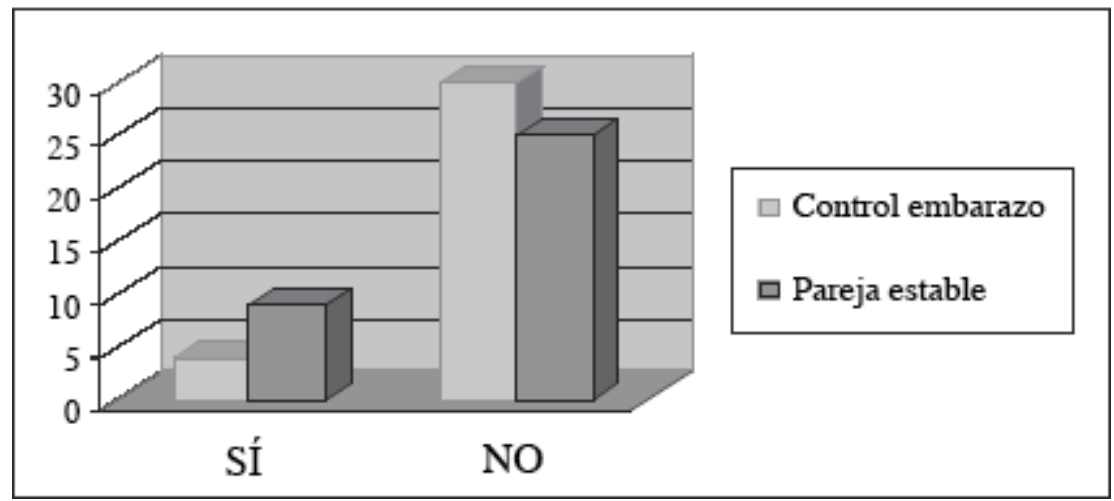


El 76,5\% había completado o cursaba enseñanza media; el 58,8\% realizó el aborto hasta las 10 semanas de gestación y el método usado fue mayoritariamente sonda y sonda más lavado jabonoso.

\section{Escolaridad $(\mathrm{N}=34)$}

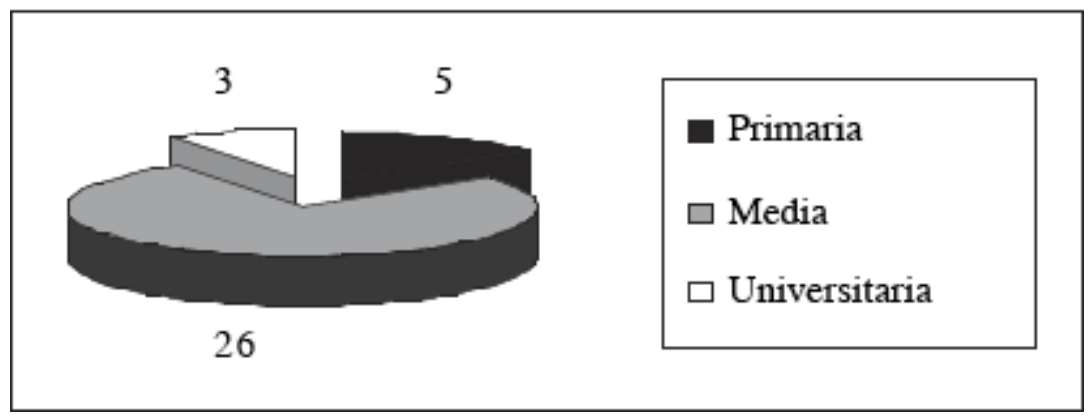

Método abortivo $(\mathrm{N}=34)$

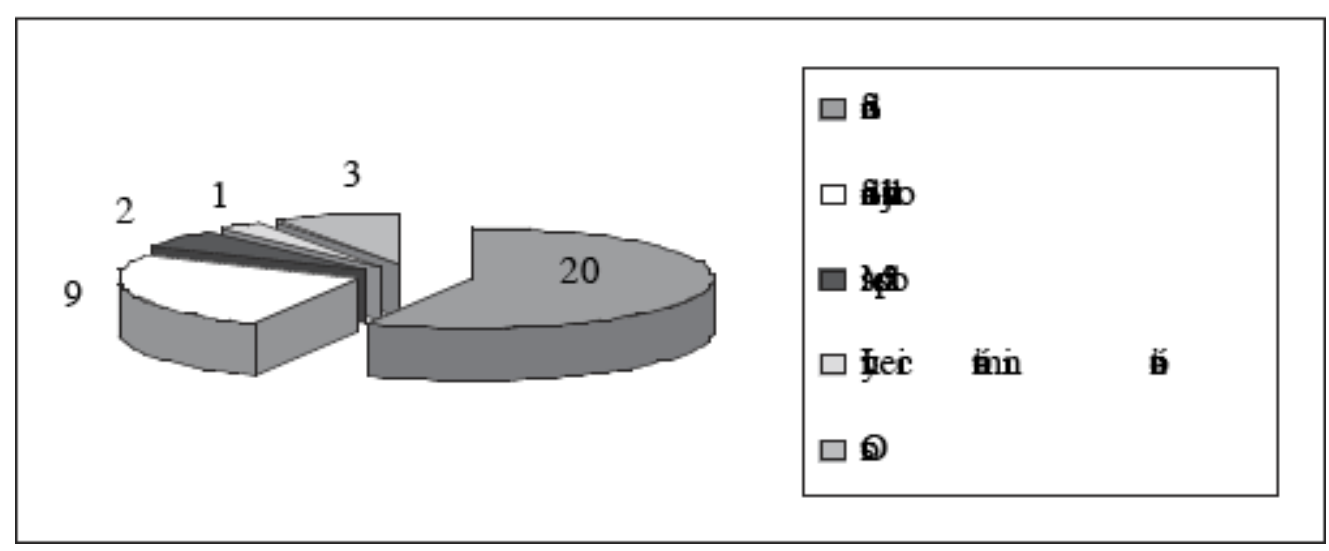

Semanas de gestación $(\mathbf{N}=\mathbf{3 4})$

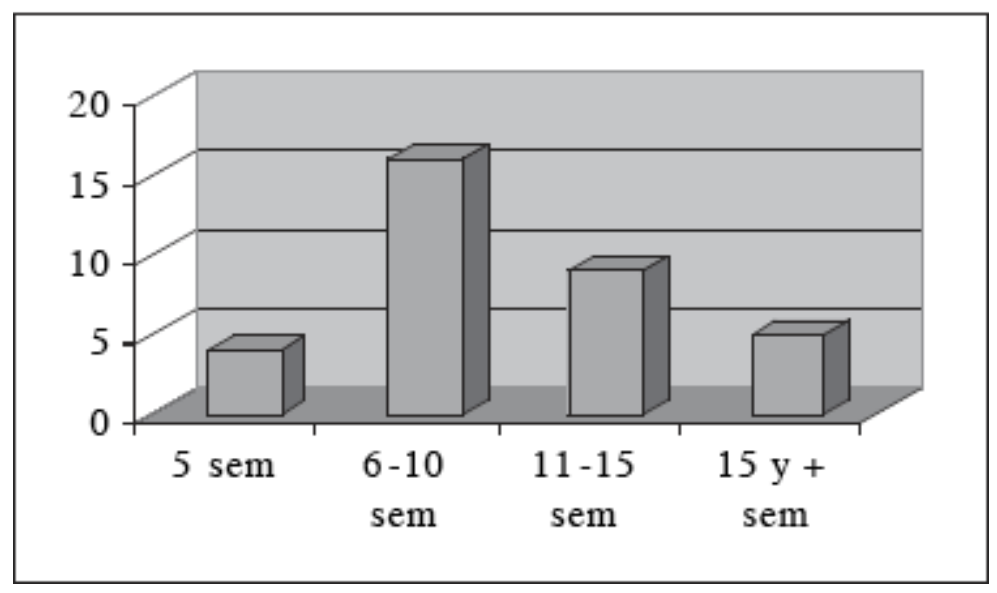

No hubo muertes maternas en el grupo descrito. 
En el aborto séptico espontáneo hay ascenso de bacterias desde la vagina que infectan las membranas y secundariamente la cavidad amniótica. Esta infección intrauterina induce la síntesis de prostaglandinas, las que a su vez inducen contracciones uterinas y también el aumento de receptores de ocitocina. Además las colagenasas bacterianas favorecen la ruptura de las membranas ovulares.

El embarazo con dispositivo intrauterino es una condición predisponente a infección porque las guías del DIU, por fenómenos de capilaridad, favorecen el ascenso de bacterias desde la vagina. Se estima que el 5\% de los abortos sépticos está asociado a la presencia de un DIU $(8,11,13)^{6}$.

La incompetencia cervical es otra circunstancia de riesgo de infección, pues al estar permeable el cuello uterino por tiempo prolongado expone a las membranas ovulares a las secreciones vaginales. El coito puede acelerar el proceso en estas pacientes (8).

\section{Maniobras abortivas $(7,8)$}

Para inducir el aborto se introducen diferentes instrumentos a través del cuello uterino, los cuales romperán las membranas o favorecerán la infección al contaminarlas con la flora vaginal o con las bacterias que transportan en su superficie. Muyrara vez se utiliza la inyección intramniótica por vía abdominal.

La introducción de sonda Nelaton es el método más usado en el 60-80\% de los casos. Esta maniobra la realiza otra persona o un familiar cercano instruido por terceras personas.

La introducción a través de la sonda de sustancias químicas, habitualmente detergentes, ocurre en el 9-20\% y en estos casos hay mayor riesgo de necrosis tisular, falla renal y alteración del sistema nervioso central.

La introducción intrauterina de otros elementos como tallos vegetales, palillos,clavos, etc., corresponde al 4-10\%. El tallo de perejil fue el más usado, probablemente por su rigidez. Por crecer en la superficie del suelo, está muy contaminado, especialmente por esporas de Clostridium perfringens.

El legrado uterino es el método usado en el 3-6\% y es más frecuente en estratos socioeconómicos altos, porque requiere de personas con mayor conocimientoy entrenamiento. Habitualmente se realiza en clínicas clandestinas.

Excepcionalmente se utiliza la inyección intramniótica de sustancias hipertónicas. 
En los últimos años el misoprostol, prostaglandina sintética, similar a la PGE1,probablemente sea uno de los métodos más usados y, a pesar de ser un fármaco de venta con receta retenida en nuestro país, es fácil de obtener. $\mathrm{Su}$ uso y venta se encuentran incluso en varios portales de internet incluyendo descripciones detalladasde dosis y efectos colaterales. Como puede usarse indistintamente por vía vaginal, rectal u oral la probabilidad de que el clínico pueda detectar su uso en un aborto aparentemente espontáneo es prácticamente imposible, a menos que se encuentren restos del fármaco en vagina, exista la confesión de su uso por la paciente, o se estéfrente a síntomas y signos de sobredosis del fármaco.

Las maniobras abortivas no necesariamente consiguen interrumpir el embarazo.El tratamiento antibiótico, en pacientes con membranas indemnes, logra el control de la corioamnionitis hasta en un 35\%. Si el embarazo continúa hay reportes de hasta $10 \%$ que logra alcanzar el término de la gestación.

El aborto ocurrirá con mayor frecuencia dependiendo del tiempo que permanecerá el elemento en el canal cervical. Si una sonda permanece por más de 33 horas en el cuello uterino el aborto se produce en el 100\% de los casos y con menos de 14 horas, con membranas indemnes, es muy probable que no ocurra.

La flora bacteriana encontrada en la cavidad uterina en los abortos sépticos es muy similar a la flora vaginal, siendo dos tercios anaerobios y un tercio bacterias aeróbicas.

Flora bacteriana encontrada frecuentemente en cavidad uterina y hemocultivos en aborto séptico

\begin{tabular}{|c|c|}
\hline Bacterias aeróbicas & Bacterias anaeróbicas \\
\hline $\begin{array}{l}\text { Escherichia coli } \\
\text { Enterococcus Streptococcus } \\
\text { grupos A, B y } \\
\text { DStreptococcus } \\
\text { viridansProteus miriabilis } \\
\text { Klebsiella Pseudomona } \\
\text { aeruginosaStreptococcus } \\
\text { aureusEnterobacter } \\
\text { Staphylococcus } \\
\text { aureusHaemophilus } \\
\text { influenzae }\end{array}$ & $\begin{array}{l}\text { Bacteroides fragilisBacteroides } \\
\text { melaninogeniccusPeptococcusClostridium } \\
\text { perfringensPeptostreptococcus }\end{array}$ \\
\hline
\end{tabular}


Copiado de: Silva S. Aborto inducido o Provocado. Obstetricia. Pérez A., Donoso E. $3^{\circ}$ Ed. Publicaciones Técnicas Mediterráneo Ltda. Santiago Chile 1999. Cáp. 29, pág. 431-450.

\section{Complicaciones del aborto}

Las complicaciones pueden ser psicológicas y orgánicas.

Desde el punto de vista psicológico está descrito un síndrome post aborto queevoluciona con depresión difícil de manejar y que puede aparecer tardíamente, inclusoaños después de ocurrido el evento y que se relaciona con el duelo no elaborado.

Las complicaciones orgánicas pueden ser variadas desde la hemorragia que es la más frecuente y cuya severidad dependerá de la edad gestacional, el tipo de maniobra realizado y la ubicación placentaria.

También puede ocurrir perforación uterina, sobre todo cuando la maniobra vadirigida a romper el saco gestacional y se utilizan elementos rígidos.

La infección es una complicación frecuente en el aborto provocado y es la principal responsable de la mortalidad asociada y de la exéresis de los órganos genitalesinternos. Esta infección puede ser simple y sólo comprometer la cavidad uterina o progresivamente dar origen a miometritis, pelviperitonitis, tromboflebitis pelviana,absceso tubo-ovárico, parametritis y celulitis del piso pelviano o absceso del fondode saco de Douglas. Cualquiera de estas formas de compromiso infeccioso puede evolucionar además con compromiso sistémico severo, ya sea por la bacteremia asociada o por las toxinas bacterianas. De este modo, podemos distinguir el shock séptico endotóxico, asociado generalmente a bacterias Gram (-) en un $60-70 \%$ y en $20-40 \%$ a gérmenes Gram (+); y la séptico toxemia por Clostridium perfringens mediada por exotoxinas.

\section{Diagnóstico}

Se debe pensar en aborto provocado frente a una embarazada febril, consangrado vaginal o rotura ovular con o sin ictericia. Pueden agregarse otros elementos epidemiológicos como embarazo no deseado, falla o ausencia de método anticonceptivo, antecedentes de aborto provocado previo o la utilización de medidas inocuas con fines abortivos. Obviamente, si hay declaración de maniobras o se trata de un embarazo con DIU, no cabe ninguna duda que estamos frente a un aborto séptico. 
La paciente con aborto séptico puede presentarse en cualquiera de las etapas dela evolución del aborto: síntomas de aborto, aborto en evolución, aborto incompleto o restos de aborto, aborto completo y también como huevo roto.

Debemos recordar también que no siempre la fiebre será un signo queestará presente, porque muchas veces junto con la maniobra abortiva se administran antibióticos que generalmente no serán los más adecuados ni en las dosis correctas.

En el examen físico general se pueden presentar varios signos clínicos como:

-Compromiso del estado general

-Fiebre, generalmente sobre $38^{\circ} \mathrm{C}$.

-Ictericia, asociado habitualmente a séptico toxemia por Clostridium perfringens. -Oliguria

-Hipotensión, taquicardia, polipnea y deshidratación

En el examen abdominal puede encontrarse desde leve dolor hipogástrico enrelación al útero hasta signos claros de pelviperitonitis y peritonitis difusa. Se debebuscar marcas de punciones abdominales a pesar de que la inyección intramnióticacon fines abortivos no es frecuente en nuestro medio.

Al examen ginecológico en la especuloscopía se debe buscar signos de ma

nipulación cervical y/o vaginal como pinzamientos o laceraciones. Puede verse un cuello uterino pálido y muy cianótico en casos de severa endomiometritis y constituye un signo muy tardío, casi terminal del curso del compromiso séptico uterino. También en la especuloscopía puede encontrarse restos ovulares o flujo purulento de muy mal olor $(7,8,9)^{7}$.

En el tacto vaginal el útero generalmente se encuentra aumentado de tamaño en concordancia con la edad gestacional si no ha ocurrido el aborto, y de menor tamaño si el aborto fue completo o incompleto. Puede encontrarse dolor uterino a la palpación o movilización cervical, siendo éste un signo de sospecha de endomiometritis o parametritis. Muy excepcionalmente puede encontrarse crepitación en el tacto vaginal en casos de infección por Clostridium perfringens.

En el laboratorio los hallazgos dependerán del grado de severidad de la infección, de manera que la leucocitosis sobre 10.000 o leucopenia en casos más graves,asociado a VHS elevada sobre 50, son frecuentes. Puede haber 
además alteracioneshidroelectrolíticas y de gases sanguíneos junto con signos de compromiso hepáticoy renal en los cuadros sépticos más severos.

La ultrasonografía puede ayudar a confirmar si el aborto fue completo, incompleto o frustro. La presencia de imágenes algodonosas o eco refringentes heterogéneas sobre 15 milímetros de diámetro antero posterior es sugerente de restos ovulares $y$, al revés, una línea endometrial homogénea de menos de 15 milímetros sugiere aborto completo $(7,8)$.

En la ecografía también puede observarse saco gestacional indemne con embrión o feto vivo, huevo roto y además nos puede permitir detectar un dispositivo intrauterino que explique el cuadro clínico de la paciente.

\section{Tratamiento}

Toda vez que se sospeche maniobras abortivas o existan signos de abortoséptico la paciente debe ser hospitalizada.

Las maniobras abortivas pueden fallar y el embarazo continuar viable. Estasituación se asocia a fiebre baja, escasa metrorragia, respuesta rápida y muyadecuada al tratamiento con antibióticos y la confirmación por ultrasonografíade indemnidad del saco gestacional. El tratamiento con antibióticos en estascondiciones debe mantenerse por 7-10 días. Debe educarse a las pacientes alalta acerca de los riesgos de nuevas maniobras y, además, acerca de los signos de persistencia de la infección, los cuales suelen manifestarse dentro del mes siguiente al alta.

El aborto séptico desde el punto de vista terapéutico y de manejo médico se clasifica en aborto de bajo riesgo y de alto riesgo.

El aborto séptico de bajo riesgo corresponde a gestaciones no mayores de 8 semanas, con fiebre por menos de 24 horas y sin compromiso miometrial, $\mathrm{ni}$ anexial, ni parametrial o peritoneal. En estos casos el tratamiento con antibióticos se mantiene por alrededor de cinco días. Los esquemas utilizados en la actualidad consisten en aminoglicósidos y un antianaeróbico estricto o una cefalosporina de tercera generación con un antianaeróbico estricto.

Se considera aborto séptico de alto riesgo a aquel que ocurre sobre las 8 semanas de gestación o que presenta fiebre por más de 24 horas, flujo purulento a través del cuello uterino en la especuloscopía o tiene signos de compromiso miometrial, anexial o peritoneal. Los esquemas antibióticos usados son los mismos, aumentando los días de tratamiento y las dosis.

En los abortos sépticos incompletos o con muerte fetal intrauterina se debe además realizar el vaciamiento uterino. El legrado o raspado uterino debe realizarseluego de 24 horas afebril o con cobertura antibiótica de 48 horas. 
Para realizar la evacuación del útero con feto muerto puede utilizarse Misoprostol en dosis de $400600 \mathrm{mcg}$., las cuales pueden repetirse c/6-8 hrs. Una vez conseguida la expulsión del feto se completa la revisión con legrado uterino. En aquellos casos en los cualesno se consigue la evacuación fetal puede utilizarse la maniobra de Krause con o sin inyección peri ovular de suero fisiológico, dependiendo de la integridad o no del saco ovular $(7)^{8}$.

Antibióticos usados en tratamiento de aborto séptico

\begin{tabular}{|c|c|}
\hline Antibiótico & Dosis \\
\hline Gentamicina & $\begin{array}{l}3 \mathrm{mg} / \mathrm{kg} \text {. IM, una dosis por } 5 \\
\text { días en aborto bajo riesgo y } 7 \\
\text { días enaborto alto riesgo. }\end{array}$ \\
\hline Clindamicina & $\begin{array}{l}20-30 \mathrm{mg} / \mathrm{kg} \text {. Oral c/8hrs por } 5 \\
\text { días en aborto bajo riesgo. } 20-40 \\
\mathrm{mg} / \mathrm{kg} . \mathrm{EV} \text { en tres dosis, por } 3 \\
\text { días y luego completar } 7 \text { días } \\
\text { oral. }\end{array}$ \\
\hline Metronidazol & $\begin{array}{l}500 \mathrm{mg} \text {. Oral c/8-6 hrs. por } 5 \\
\text { días en aborto bajo riesgo. } 500 \\
\text { mg. c/8-6 hrs. EV por } 48 \text { hrs. y } \\
\text { luego completar } 7 \text { días oral }\end{array}$ \\
\hline Ceftriaxona & $\begin{array}{l}1 \text { gr. c/12 hrs. EV por } 24-48 \text { hrs. } \\
\text { y luego. } 1 \text { gr. c/ } 24 \text { hrs. EV hasta } \\
\text { completar } 7 \text { días.Sólo se utiliza } \\
\text { en aborto de alto riesgo. }\end{array}$ \\
\hline Penicilina G sódica & $\begin{array}{l}5 \text { mill. c/6 hrs. EV, en bolo, por } \\
48-72 \text { hrs. y luego } 2 \text { mill. c/6 } \\
\text { hrs. EV o IM hasta completar } 7 \\
\text { días. }\end{array}$ \\
\hline Imipenem & $\begin{array}{l}60 \mathrm{mg} / \mathrm{kg} . \mathrm{EV} \text { en } 4 \text { dosis por } 7 \\
\text { días, reservado para pacientes } \\
\text { alérgicos a Penicilina y graves } \\
\text { en sepsis por Clostridium } \\
\text { perfringens. }\end{array}$ \\
\hline
\end{tabular}

Extraído de: Silva S. Infecciones en Ginecología y Obstetricia. Publicaciones Técnicas Mediterráneo Ltda. Santiago. Chile 1997, pág. 179-218.

Shock séptico, shock endotóxico en aborto séptico 
Es una alteración severa de la homeostasis de etiología infecciosa, que se asociaa un trastorno metabólico celular grave secundario a una prolongada e importante alteración de la perfusión tisular.

Puede verse esta complicación en cerca del $2 \%$ de los abortos y es dos veces más frecuente que la séptico toxemia por Clostridium perfringens. En reportes de nuestro servicio el $70 \%$ corresponde a shock endotóxico y $30 \%$ a séptico toxemia por Clostridium perfringens $(14,15)$.

Las endotoxinas son lipopolisacáridos que forman parte de la pared celular delas bacterias Gram negativas y son el principal mediador asociado a la génesis de esta complicación. También existen otros mediadores que pueden provocar fenómenos semejantes, como la toxina 1 del shock tóxico producido por Staphylococcus y antígenos virales y fúngicos.

Otros mediadores importantes y demostrados en modelos experimentales sonel factor de necrosis tumoral-alfa y la interleukina-1 $(7,8,9)^{9}$.

Las endotoxinas actúan sobre el endotelio vascular y el sistema linfomonocitario, induciendo la producción de mediadores que dañarán el propio endotelio y generarán un potente efecto vasodilatador, aumentando, además, la capacitancia y la permeabilidad capilar. Estos efectos son fundamentales en el inicio de la alteración fisiopatológica del shock, por el paso de macromoléculas proteicas y líquido al espacio extravascular e intersticial.

A nivel celular se produce una serie de mediadores de la respuesta infamatoriaque serán los responsables de los fenómenos fisiopatológicos en diferentes niveles del organismo (ver diagramas). 
Fisiopatología del shock séptico. Alteración a nivel celular $(8)^{10}$.
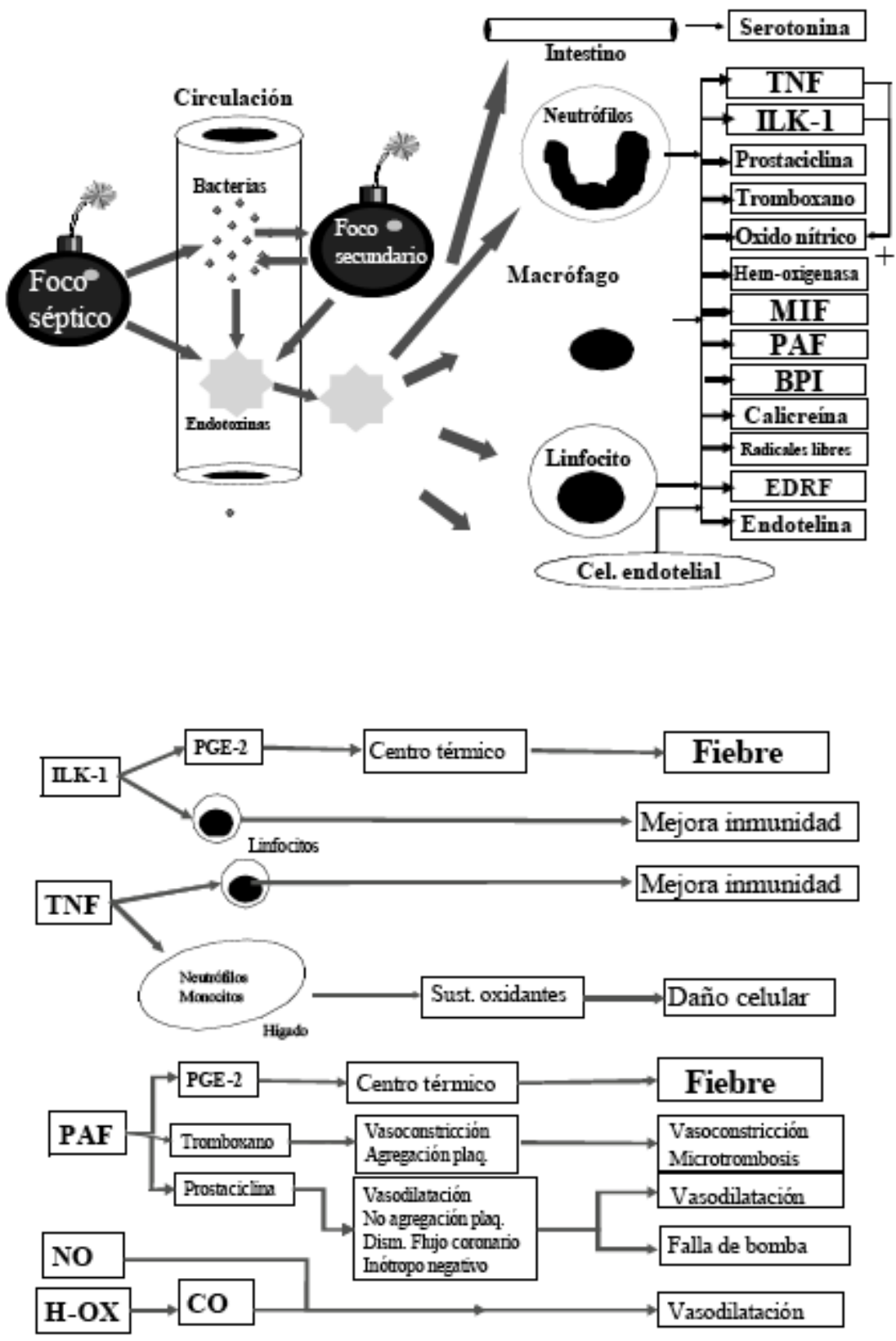

A nivel plasmático se activan algunos componentes del complemento, siendo el más importante el C3, que al no estar presente agrava aún más el shock. Además se activa la cascada de la coagulación a través de su vía intrínseca, lo que puede jugar un rol importante cuando se agrega coagulopatía de consumo que puededesencadenar la muerte de la paciente. 
En la microcirculación se produce aumento de la resistencia vascular y por consiguiente disminución de la velocidad de circulación por agregación de eritrocitos y leucocitos. Esto agrava más el aumento de permeabilidad capilar.

En la macrocirculación existe inicialmente un estado hiperdinámico aumentando el gasto cardíaco, disminuyendo la resistencia periférica y aumentando el flujo en la microcirculación. Posteriormente hay disminución del flujo esplácnico, renal, hepático, intestinal, pulmonar, cardíaco y cerebral, agravando el daño tisularen estos órganos.

Aparentemente no es la bacteria ni la endotoxina lo que genera la hecatombe en el organismo sino la respuesta frente a la noxa. Los múltiples mediadores generados celularmente pueden ocasionar una respuesta adecuada con un efecto benéfico, y en otros casos condicionar una respuesta inflamatoria inadecuada con daño tisular y, en los casos más severos, la muerte.

Todos estos fenómenos originan una hipovolemia relativa, la cual puedeagravarse aún más si se considera el sangrado o metrorragia que acompaña al aborto. Por ello la corrección de la hipovolemia juega un rol fundamental en elmanejo del shock por aborto. Cuando no se corrige la hipovolemia y el factor séptico no está controlado la hipotensión será más grave y como un mecanismo compensatorio ocurrirá vasoconstricción. El riñón será uno de los órganos queprimero se altere frente a esta circunstancia y el débito urinario caerá progresivamente, lo cual puede anticiparse como signo de hipoperfusión en otros órganosmás nobles.

\section{Cuadro clínico}

Se describen tres etapas en el shock séptico.

El pre-shock séptico es el inicio del proceso. Clínicamente se manifiesta con fiebre,leucocitosis con desviación a izquierda o leucopenia; disociación pulsotemperatura;taquicardia; polipnea; presión arterial normal o baja; piel fría y pálida; disminución del llene capilar; disminución del débito urinario; obnubilación del sensorio. 
En la medida que se agrava el cuadro aparece el shock séptico, que se caracteriza por agravamiento de los parámetros anteriores y el desarrollo de acidosis metabólica. El compromiso metabólico progresivo compromete otros órganos. En el intestino la isquemia aumenta el paso de bacterias y enterotoxinas a la circulacióny puede haber hemorragias. A nivel hepático hay déficit de producción energética y de mecanismos inmunitarios. En el pulmón se produce edema intersticial de la pared alveolar, lo cual disminuye progresivamente el intercambio gaseoso y puede aparecer acidosis respiratoria, que sumada a la acidosis metabólica disminuye la expectativa de vida de la paciente. Los cambios que simultáneamente se estánproduciendo a nivel del endotelio capilar agravan la hipotensión por paso de agua al extravascular.

Si no se consigue el control del shock séptico se agrega la alteración de la coagulación, que va a estar determinada por la formación de microtrombos en la microcirculación que consumen factores de coagulación. Los microcoágulos puedenembolizar y aumentar más la falla respiratoria. Las pruebas de coagulación se alteran y aparecen fenómenos hemorragíparos multifocales. Posteriormente, y en la medida que la alteración celular es mayor, la membrana de los lisosomas se altera y liberan al citoplasma y la circulación de enzimas proteolíticas que destruyen las células y provocan mayor vasodilatación en el aparato circulatorio aumentando aún más la hipotensión. A nivel pancreático, por isquemia se produce el factor de depresión miocárdico que provoca falla central. Estamos en presencia del shock progresivo o refractario y cuya consecuencia es la muerte.

\section{Tratamiento}

Las medidas utilizadas en el tratamiento del shock van orientadas al control de los efectos de la bacteremia y la endotoxemia y no a la causa originaria, salvo el uso de los antibióticos.

En las medidas generales se encuentra el reposo absoluto y semisentadaademás del régimen cero. Hidratación parenteral. Debe mantenerse control estrictode signos vitales incluyendo diuresis y frecuencia respiratoria. Control de presión venosa central (PVC) y en algunos casos medir presión de enclavamiento concatéter Swan Ganz.

Las medidas específicas van a tratar de controlar la infección, mantener la volemia, la función renal, la función respiratoria, corregir el equilibrio ácidobase y electrolítico y la coagulopatía.

El tratamiento antibiótico corresponde al usado para los abortos sépticos de alto riesgo. 
El manejo de la volemia se realiza inicialmente con soluciones cristaloides, y se efectúa mediante la infusión rápida de solución fisiológica de cloruro de sodio, $500 \mathrm{ml}$. en 20-30 minutos. Si no se consigue diuresis adecuada debe realizarse prueba de sobrecarga acuosa, previa instalación de catéter venoso central. Con PVCmenor a $10 \mathrm{~cm}$ de agua se deben pasar $300 \mathrm{ml}$ de cristaloides en 10 minutos. Si PVCestá entre 10 y 14 se administran 100-200 $\mathrm{ml}$ de suero en 10 minutos, y si PVC es mayor a 14 la velocidad de infusión para esta prueba es de $50 \mathrm{ml}$ en 10 minutos. Si la respuesta es inadecuada deben utilizarse coloides y descartar anemia aguda que puede ser secundaria a la metrorragia que acompaña al aborto. Habitualmente en el shock séptico por aborto basta con monitorizar la PVC para evaluación de la bomba cardiaca. Si fuese necesario un Swan Ganz, debe manejarse en unidad de tratamiento intensivo. Es aconsejable además instalar un catéter arterial para medir la PAM; además permite tomar muestras seriadas de sangre para el control de exámenes de laboratorio.

La función renal es muy importante en el manejo del shock y debe mantenerseun control estricto del débito urinario. Lo ideal es mantener diuresis entre 40-60 ml/hora. Si luego de restablecer volemia no se consigue diuresis adecuada debe plantearse el uso de drogas vasoactivas y diuréticos con estricto control en unidad de pacientes críticos. La medición del sodio urinario y la osmolaridad puedenutilizarse como control de hipoperfusión renal.

La alteración ácido-base inicial es alcalosis respiratoria secundaria a lahiperventilación por la bacteremia. Posteriormente, si la hipoperfusión tisularcontinúa, aparecerá acidosis metabólica. Lo ideal es mantener a la paciente con pHde 7.35-7.50, $\mathrm{PaCO}_{2}$ de 30-40 mm. Hg. y bicarbonato de 20$26 \mathrm{mEq} / \mathrm{L}$. Cuando la alteración ácido-básica no es muy severa, basta corregir la perfusión tisular para mejorar aquélla, de lo contrario se deberá administrar bicarbonato cuando el $\mathrm{pH}$ baja de 7.2 y el BE supera los $-15 \mathrm{mEq} / \mathrm{L}$.

Desde el punto de vista respiratorio se debe considerar que casi todas las pacientes en shock se benefician de la administración de oxígeno. Se debe mantener $\mathrm{PaO}_{2}$ sobre $80 \mathrm{~mm}$.Hg., y debe administrarse oxígeno por máscara cuando la $\mathrm{PaO}_{2}$ está bajo $80 \mathrm{~mm}$.Hg. La utilización de ventilación mecánica está indicada cuando:

$-\mathrm{PaCO}_{2}$ sobre 45-50 mm.Hg., si hay acidosis metabólica.

$-\mathrm{PaCO}_{2}$ sobre 50-55 mm.Hg., si el bicarbonato es normal, lo que indica acidosis respiratoria.

$-\mathrm{PaO}_{2}$ menor de $60 \mathrm{~mm} . \mathrm{Hg}$. , con oxígeno al $40 \%$.

-Frecuencia respiratoria sobre 35 por minuto 
-Excesivo esfuerzo respiratorio por agotamiento de la paciente.

Para el manejo de la coagulopatía lo ideal es tratar de revertir el shock. Una vez establecida se deben administrar factores de coagulación según los controles seriados de laboratorio.

Dentro del tratamiento del shock séptico por aborto también debe considerarsela cirugía como una herramienta más de la terapia. En esta situación, siempre la cirugía será resectiva, porque su objetivo será eliminar el foco séptico.

Una vez considerada esta decisión no debieran pasar más de dos horas para realizarla.

La indicación de cirugía se considera frente a persistencia del shock séptico a pesar del tratamiento y por complicaciones asociadas al aborto como perforación uterina, endomiometritis, abscesos pelvianos o peritonitis. El tratamiento quirúrgicoincluye histerectomía total y salpingectomía bilateral. Los ovarios no se resecan a menos que estén formando parte de un absceso tubo-ovárico.

\section{Septicotoxemia por Clostridium perfringens}

Es una forma clínica particular del aborto séptico en la cual el agente etiológico es el Clostridium perfringens, bacilo Gram positivo, anaerobio estricto. Las manifestaciones del cuadro clínico se asocian a las diversas exotoxinas producidas por la bacteria que producen mionecrosis, miocarditis y hemólisis.

La tasa de mortalidad es muy alta, cercana al 50\%, y su letalidad es de $30 \%$ $(15)^{11}$. La letalidad está relacionada con el grado de hemólisis y lo tardío del diagnóstico. Corresponde al 0,3-1,6\% de los abortos sépticos.

El diagnóstico es principalmente clínico. Se han descrito tres formas que se relacionan con la mortalidad y la rapidez de evolución:

- Hiperaguda o fulminante

- Aguda

- Síndrome ictero-hemolítico que cursa como un aborto séptico, con ictericia y anemia leve. Es la forma más benigna y su diagnóstico sólo se realiza por cultivo, que permite identificar al Clostridium como agente causal. 
Las formas aguda y fulminante evolucionan con hipotensión, taquicardia,hipotermia e ictericia. Esta última está presente en el 100\% de las pacientes, y en general es moderada y puede aumentar rápidamente en concomitancia conla caída del hematocrito. La hemólisis puede observarse en el hemograma. Lahemoglobinuria está presente en el $90 \%$ de los casos y se asocia con frecuencia a insuficiencia renal aguda.

Otro signo frecuente es la mialgia, que puede verse en el $60 \%$.

El pronóstico dependerá del poder patógeno del Clostridium, la edad gestacional del embarazo, el intervalo entre la maniobra y la consulta de la paciente, y el intervalo entre el diagnóstico y el inicio del tratamiento o la cirugía.

\section{Exotoxinas}

2) Falla renal por necrosis tubular que se observa en el $50 \%$ de los casos y se debe a daño tubular por filtración y reabsorción de exotoxinas, hemoglobina y mioglobina y productos de necrosis tubular, condición que en general es reversible. También se debe a isquemia por hipoperfusión renal y por obstrucción tubular por cilindros de hemoglobina.

Cuando se produce necrosis cortical la anuria es casi siempre irreversible, y si la paciente sobrevive quedará con daño renal permanente y en diálisis crónica.

En estas pacientes el tratamiento oportuno y la indicación de cirugía precoz ayudan a evitar estas complicaciones y mejoran las expectativas de sobrevida.

\section{Conclusiones}

El aborto séptico en nuestro país en la actualidad no constituye un problema de salud relevante. Desde la década de los años 1960 en adelante y asociado a las diversas políticas sanitarias implementadas gubernamentalmente, la tasa demortalidad materna por aborto ha disminuido significativamente, mucho más de lo que se explicaría sólo por el uso de métodos anticonceptivos. Probablemente todo el desarrollo social y económico de las últimas décadas también ha influido de manera importante en estos indicadores de salud (1, 2, $3,4,5,6)^{12}$.

Es tan baja la prevalencia de esta patología que muchas de las antiguas unidadesde patología séptica ginecológica han desaparecido de los grandes hospitales. En nuestro hospital la unidad de "Aislamiento Ginecológico", que concentraba fundamentalmente las pacientes con abortos sépticos, dejó de funcionar como tal hacevarios años y pasó a formar parte de la unidad de Ginecología General. Hace variosaños también que no hemos tenido muertes maternas asociadas al aborto séptico, y la última paciente fallecida fue una 
adolescente de 15 años con septicotoxemia por Clostridium perfringens secundaria a un aborto provocado clandestinamente con sonda intrauterina y que ingresó a nuestro servicio con un severo cuadro de coagulación intravascular diseminada.

No se puede desconocer tampoco que el acceso a la información, a través de los portales de internet, permite que se pueda obtener el misoprostol de manera fácil, transformándose probablemente en uno de los métodos abortivos de elección,con pocas complicaciones sépticas y difícil de reconocer para el clínico si no se obtiene la confesión de la paciente o se encuentran signos de sobredosis o restos del producto en el examen ginecológico.

El tratamiento de esta patología sigue estando basado en el control de la infección con antibióticos y/o cirugía y en el manejo de la hemodinamia, el control del equilibrio ácido-básico y electrolítico, además de la mantención de la función renal y pulmonar y la corrección de las alteraciones de la coagulación.

El gran desarrollo de las unidades de pacientes críticos, con todo el avance tecnológico de los últimos años, también permite ofrecer una mejor expectativa de tratamiento y sobrevida para aquellas mujeres con cuadros sépticos más severos.

La cirugía cuando es requerida debe ser realizada con prontitud, antes dellegar al período de irreversibilidad del shock, y lamentablemente sigue siendo resectiva y de alguna manera "mutilante" para la mujer, pues significará siempre histerectomía y al menos salpingectomía bilateral.

\section{Citas}

${ }^{1}$ Donoso E. ¿Unsafe Abortion en Chile? Rev. Chil. Obstet Ginecol. 2008: 73(6): 359-361.Szot J., Moreno C. Mortalidad por aborto en Chile. Análisis epidemiológico 1985-2000. Rev Chil Obstet Ginecol 2003; 68(4): 309-314.

${ }^{2}$ Donoso E. ¿Unsafe Abortion en Chile? Rev Chil Obstet Ginecol 2008; 73(6): 359-361. Szot J., Moreno C. Mortalidad por aborto en Chile. Análisis epidemiológico 1985-2000. Rev Chil Obstet Ginecol 2003; 68(4): 309-314. Donoso E. Mortalidad Materna en Chile, 2000-2004.Rev Chil Obstet Ginecol 2006; 71(4): 246-251. Szot J. Reseña de la Salud Pública Materno Infantil Chilena durante los últimos 40 años: 1960-2000. Rev Chil Obstet Ginecol 2002; 67(2): 129-135. 
${ }^{3}$ Espinoza L., et al. Estudio clínico epidemiológico del aborto en mujeres chilenas. Rev. Chil. Obstet Ginecol. 1985; 50: 278-285.

${ }^{4}$ Silva S. Infecciones en Ginecología y Obstetricia. Publicaciones Técnicas MediterráneoLtda. Santiago. Chile 1997, pág. 179-218. Silva S. Aborto inducido o Provocado. Obstetricia

${ }^{5}$ Sandoval O. Datos no publicados. Abortos 1999-2000 Hospital Dr. Sótero del Río.

${ }^{6}$ Silva S. Infecciones en Ginecología y Obstetricia. Publicaciones Técnicas MediterráneoLtda. Santiago. Chile 1997, pág. 179-218. Silva S. Aborto inducido o Provocado. Obstetricia Pérez A., Donoso E. $3^{\circ}$ Ed. Publicaciones Técnicas Mediterráneo Ltda. Santiago Chile 1999. Cáp. 29, pág. 431-450. Ovalle A. et al. Bacteriología, evolución, hallazgos histoplacentarios, miometriales e histerográficos del huevo infectado entre las 10 y 26 semanas. Rev Chil Obstet Ginecol 1983; 48(6): 449-462. Silva S. et al. Bacteriología del aborto séptico en una comunidadsuburbana. Rev Chil Obstet Ginecol 1996; 61: 22-27.

${ }^{7}$ Silva S. Infecciones en Ginecología y Obstetricia. Publicaciones Técnicas MediterráneoLtda. Santiago. Chile 1997, pág. 179-218. Silva S. Aborto inducido o Provocado. Obstetricia Pérez A. Donoso E. $3^{\circ}$ Ed. Publicaciones Técnicas Mediterráneo Ltda. Santiago Chile 1999. Cáp. 29, pág. 431-450. Sweet R., Gibbs R. Postabortion Infection, Bacteremia and Septic Shock.Infectious diseases of the female genital tract. $4^{\circ}$ Ed. Lippincott Williams and Wilkins. 2002. Philadelphia USA. Cáp. 13: 355-367.

${ }^{8}$ Silva S. Infecciones en Ginecología y Obstetricia. Publicaciones Técnicas MediterráneoLtda. Santiago. Chile 1997, pág. 179-218.

${ }^{9}$ Silva S. Infecciones en Ginecología y Obstetricia. Publicaciones Técnicas MediterráneoLtda. Santiago. Chile 1997, pág. 179-218. Silva S. Aborto inducido o Provocado. Obstetricia Pérez A. Donoso, E. $3^{\circ}$ Ed. Publicaciones Técnicas Mediterráneo Ltda. Santiago Chile 1999. Cáp. 29. pág. 431-450. Sweet R., Gibbs R. Postabortion Infection, Bacteremia and SepticShock. Infectious diseases of the female genital tract. $4^{\circ}$ Ed. Lippincott Williams and Wilkins. 2002. Philadelphia USA. Cáp. 13: 355-367. López X. et al. Shock endotóxico en aborto séptico.Rev Chil Obstet Ginecol 1985; 50(5): 412-9. López X. et al. Septicotoxemia por clostridium perfringens. Rev Chil Obstet Ginecol 1985; (5): 396-402.

${ }^{10}$ Silva S. Aborto inducido o Provocado. Obstetricia Pérez A. Donoso E. $3^{\text {a }}$ Ed. Publicaciones Técnicas Mediterráneo Ltda. Santiago Chile 1999. Cáp. 29, pág. 431-450. 
${ }^{11}$ López X. at al. Septicotoxemia por clostridium perfringens. Rev Chil Obstet Ginecol 1985; (5): 396-402.

${ }^{12}$ Donoso E. ¿Unsafe Abortion en Chile? Rev. Chil. Obstet Ginecol 2008; 73(6): 359-361.Szot J., Moreno C. Mortalidad por aborto en Chile. Análisis epidemiológico 1985-2000, Rev Chil Obstet Ginecol 2003; 68(4): 309-314. Donoso E. Mortalidad Materna en Chile, 20002004. Rev Chil Obstet Ginecol 2006; 71(4): 246-251. Donoso E. Plan de acción regional para la reducción de la mortalidad materna en las Américas: Resultados de Chile. Rev Chil Obstet Ginecol 2003; 68(1): 13-16. Faúndez A. La iniciativa de FIGO para la prevención del aborto inseguro. Rev Chil Obstet Ginecol 2008; 73(4): 221222. Szot J. Reseña de la Salud Pública Materno Infantil Chilena durante los últimos 40 años: 1960-2000. Rev Chil Obstet Ginecol 2002: 67(2): 129-135. 